Loading

The Journal of the Canadian Game Studies Association

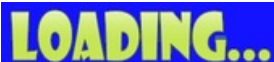

\title{
Videogame Production: How the Capitalist Socius and Platformization Subjectivate
}

\section{Joshua Jackson}

Volume 12, Number 19, Winter-Spring 2019

URI: https://id.erudit.org/iderudit/1058320ar

DOI: https://doi.org/10.7202/1058320ar

See table of contents

Publisher(s)

Canadian Game Studies Association

ISSN

1923-2691 (digital)

Explore this journal

Cite this article

Jackson, J. (2019). Videogame Production: How the Capitalist Socius and Platformization Subjectivate. Loading, 12(19). https://doi.org/10.7202/1058320ar

\section{Article abstract}

Diverse representations of bodies in videogames has become a point of contention among developers and consumers alike, which has lead scholars to question why videogame production is breaking with trends of recognizable, anthropocentric characters in favor of "diverse" bodies. This paper contends that the overarching reason for this is that the capitalist socius (Deluze and Guattari, 1986) has become more readily equipped to be able to monetize and streamline diversity away from being an act of subversion and into an easily manipulatable source of revenue. In examining how the capitalist socius overlays onto the videogame production process, a few things become apparent. Because videogame production operates within the capitalist socius, their goals are the similar: to become autopoietic (able to reach a point of homeostasis in which the entity is able to reproduce and maintain its structural integrity) and to turn any and all resources into sources of capital generation. The expectation of bodies working in these regimes is to be as non-threatening and as pliable to new modes of subjectivation and capital generation as possible, but that means that bodies must undergo certain political transformations to adhere to these needs of the capitalist socius and videogame production process. As with any hegemonic structure, there are pockets of resistance that look to buck the current trends of subjectivation and capital generation. The form of resistance this paper examines is personal-games and affective experiences, but as with most things pertaining to the capitalist socius, personal-games are dangerously close to being swept up, monetized, and crunched down.
This document is protected by copyright law. Use of the services of Erudit (including reproduction) is subject to its terms and conditions, which can be viewed online.

https://apropos.erudit.org/en/users/policy-on-use/ 


\title{
Videogame Production: How the Capitalist Socius and Platformization Subjectivate
}

\author{
Joshua Jackson \\ North Carolina State University \\ jajacks5@ncsu.edu
}

\begin{abstract}
Diverse representations of bodies in videogames has become a point of contention among developers and consumers alike, which has led scholars to question why videogame production is breaking with trends of recognizable, anthropocentric characters in favor of "diverse" bodies. This paper contends that the overarching reason for this is that the capitalist socius (Deluze and Guattari, 1986) has become more readily equipped to be able to monetize and streamline diversity away from being an act of subversion and into an easily manipulatable source of revenue. In examining how the capitalist socius overlays onto the videogame production process, a few things become apparent. Because videogame production operates within the capitalist socius, their goals are the similar: because global physical proximity no longer means much in how games and culture interact, heterogeny has become important to how videogame production operates. By subjectivizing workers to value and maintain hypermasculinity, anti-femininity, and a suite of other negative tropes in videogame production, the capitalist socius has created a selfpolicing workplace culture that seeks to displace any bodies that do not fall in line with the culture. In examining platformization as another facet of the capitalist socius' control over videogame production spaces, it becomes clear that there are more far-reaching implications for why hypermasculinity, anti-femininity, etc. subsist. By examining Fisher and Harvey's (2013) case study about an incubator in Toronto, issues in platformization in videogame production become more apparent, but ways in which revolutionary acts that seek to usurp the capitalist socius' ability to consume and monetize become equally as apparent, and even more important for future scholars to understand.
\end{abstract}

\section{Author Keywords}

Capitalist socius, videogame production, workplace culture, integrated world capitalism, diversity, platform governance 


\section{Videogame Production: How the Capitalist Socius and Platformization Subjectivate}

In recent years, representations of diverse body types in videogames has become a point of contention for many North American triple-A videogame developers. For example, BioWare's popular series' Dragon Age and Mass Effect offer players both heterosexual and homosexual romance options and have pushed back on anthropocentric character design to some extent. Some scholars question the sincerity with which companies are representing diverse body types and are concerned that these attempts at diversity are simply these companies trying to monetize diversity with no care given to how those representations actually affect consumers (Condis, 2015; Behm-Morawitz \& Mastro, 2009; Shaw, 2014; Ruberg \& Shaw, 2017). These sudden shifts in design choices raise some questions: Why are developers suddenly breaking nearly 40 years of character-creation tropes that dictate recognizable, identifiable, homogenized and anthropocentric characters? Why is diversity often poorly rendered and seemingly an afterthought? These representations of diversity indicate that the industry views both real and virtual bodies as objects of capital-generation: as issues of social justice and equity have become important points of discussion in videogame production (Chess, Evans, \& Baines, 2017; Chess, 2016; Shaw \& Chess, 2017; Fisher \& Harvey, 2013; Lauteria, 2012), in-game assets can easily be shifted to appear equitable and inclusive, and that inclusivity can be marketed. Until the market started to shift in taste, hyper-masculinity, hypersexualized female bodies, and general anti-feminism were tools for commercial success (Shaw, 2011; Shaw, 2014, Behm-Morawitz \& Mastro, 2009, Kennedy, 2002). The spaces in which triple-A games are made are oriented around male bodies because the majority of the workers in triple-A development spaces are male (Johnson, 2013b; Dyer-Witheford \& De Peuter, 2006).

I contend that the main reason that the videogame industry is attempting to diversify is that the capitalist socius (Deleuze \& Guattari, 1983) is becoming better and better equipped to consume and monetize forms of diversity more readily. According to Deleuze and Guattari (1983), the capitalist socius is a social 'body', or an assembly of productive social entities that are responsible for production of resources. In the case of late-stage capitalism, the resource being produced is monetizable units of cultural production. The videogame production industry is firmly ensconced in systems of capitalism: precarity in production labour that forces workers to work themselves well past exhaustion or face replacement (Bulut, 2014, 2015; Kerr \& Kelleher, 2015; Williams, 2013, 2018; Westar \& Legault, 2017), outsourcing to third-world asset firms (Hyman, 2008), and the use of passion for videogames as an industry recruitment and retention tool and as a gate keeping mechanism for employee progress (Bulut, 2014, 2015; Johnson, 2018; Deuze, Martin, \& Allen, 2007; Kerr \& Kelleher, 2015; Kuchlich, 2005; Sotaama, 2007; Parker, Witson, \& Simon, 2017). The work hours during production cycles are grueling (Johnston, 2013b; Dyer-Witheford \& De Peuter, 2006; Bulut, 2014, 2015; Llerena, Burger-Helmchen, \& Cohendet, 2009), the work environments reinforce negative binaries such as hyper-masculinity and anti-feminism (Johnston, 2013a; Fisher \& Harvey, 2013; Hacker, 1979, 1981; Salter \& Blodgette, 2012) and bodies are readily axiomatized as sources of capital (Jenson \& de Castell, 2018; Gallagher, Jong, \& Sinervo, 2017; DiSalvo et al, 2007), meaning that, as social and cultural issues reach a threshold of recognizability in society at large, the bodies in question in that movement become more easily subjectivizable and exploitable. I recognize that there are many types of bodies in videogame production that deserve the due diligence of understanding their place in the capitalist socius, but for this paper, I will be focusing on the human body. 
Specifically, the human bodies at work creating videogames, the emotional, physical, and psychical labour exerted by those bodies, and how, through platform governance (Nieborg \& Pell, 2018), those labour forms are continually reconfigured to best serve capital production which then creates a working culture of modularity. Additionally, understanding how platformization allows for easy monetization of social and cultural trends becomes an important part of how we can recontextualize the capitalist socius' ways of processing and monetizing new social issues in videogames.

In this paper, I start by looking at how the capitalist socius overlays onto videogame production and consumption and how the two function in a Guattarian notion of integrated world capitalism', meaning that physical proximity no longer plays a substantial role in capital production, nor in social and cultural production. Instead, influence intermingles across a world stage, and through platformization, social and cultural production become heterogenous across international boundaries (Guattari, 1981). Next, I examine the ways in which the videogame production and consumption process mimics the more insidious aspects of the capitalist socius through conditioning consumers to think/act/perpetuate certain things and actions (or become subjectivized by that media), the creation of heterogonous material, and the dualism of production and anti-production. Next, I will explore how platformization contextualizes cultural and social heterogony as a positive thing; an easily steerable, more easily monetizable, cultural production pipeline that is not concerned with granular differences, needs, and social mores of potential audiences (Reuver, Sørenson, \& Basole, 2018; Barwise \& Watkins, 2018). Next, I will examine a case study from Fisher and Harvey (2013) about an incubator in Toronto that sought to be an entry point for women into the videogame production industry. Contextualizing this case with work from other Canadian games scholars allows us to understand how platformization and the capitalist socius allow for negative tropes to be embedded and used as training techniques, even when seeking to train marginal bodies for entry into videogame production. Finally, I will use the tools that Fisher and Harvey's (2013) case study developed to examine two unique areas of videogame production that are evolving in such ways as to impede the progress of the capitalist socius: game development groups like Dames Making Games (DMG), and international unionization efforts of videogame production workers.

By understanding how the Deleuzoguattarian terms I cover, when applied to an understanding of platformization, create an inherently new understanding of videogame production, this paper provides a new formative framework for examining how videogame production is more complicit in perpetuating negative tropes that feminist game studies scholars have identified than academic work has given it credit for. Since access to videogame production spaces presents its own suite of methodological problems, understanding how videogame production works in a theoretical, abstracted sense could provide future scholars with ways of conducting grounded research that does not necessarily rely on being embedded in those spaces.

\section{The Capitalist Socius, Videogame Production, Integrated World Capitalism}

Deleuze and Guattari (1983) provide a way of contextualizing how capitalism, as a social construct, came to be through characterizing the historical transformations of property ownership and ruling relations as first a 'savage' socius, then as a 'despotic' socius, and finally, as a 'capitalist' socius. The savage socius was organized around tribal relations: bodies are marked in ceremonies, which then insert those bodies into 'clans' from which products are traced. Land is 
claimed by tribes, that land is credited with production of materials in a symbiotic relation to the clan itself. As societies set down roots, and land claims became more routinized, the despotic socius formed. As land is amassed, warred over, and conquered, clan-land production loses its claim and instead empire-rule is the way of the world. As more land is acquired and mixed together, single-clan claims for production are no longer honored, and thus a new attribution model needed to be made. In the despotic socius, this became the despot, or the divine father of the people over whom he ruled. Production (in this case, production means land seizure as well as actual, material production) is attributed to the despot. The capitalist socius is a complete departure from the savage and despotic sociuses that Deleuze and Guattari discussed in AntiOedipus (1983). Whereas the savage and despotic sociuses were concerned with culturating their citizens and establishing hierarchies of dominance, the capitalist socius's main goal is production, and it relies on outside means to overload bodies with information, or overcode, and to force those bodies into willingly perpetuating the cycle, or subjectivation, of the product that is being created. In the case of this paper, I am speaking of videogame production. The capitalist socius overloads bodies with cultural markers regarding videogames (they're fun, they're cool, when you make them all you do is play at work, etc.) to overcode those bodies into becoming productive bodies that must adhere to the idea that videogames, and videogame production, have to be the way that they are and must be guarded, lest their form of subjectivation that is allowing them to survive in capitalist society becomes threatened. Basically, the capitalist socius has created a working culture that perpetuates itself through enculturating new bodies into believing that the current way of producing videogames is the only valid way, and those bodies gatekeep so that the capitalist socius itself doesn't have to step in to control the bodies in question; instead, it is allowed to take up the task of further overcoding other bodies and creating more flows of production. By quantifying production in the sphere of videogames, the capitalist socius creates a space where the inherent purpose of the bodies that work within it is to connect deterritorialized flows of labor, meaning that instead of working toward a community's communal interest, like in the savage and despotic sociuses, workers are subjectivated to overproduce and not expect to take part in the bounty of overproduction. The excess that is produced is not redistributed equally to workers, but instead is hoarded by a select few bodies. This hoarding is done in a bid to further strip the identities of the bodies working within the capitalist socius and to create bodies that are conditioned to produce, expect little in the way of recompense, but always have the proverbial carrot on a string of "one day you too could own your own studio or make your own game, you just have to work harder".

The videogame industry overlays onto the capitalist socius very well. Peticca-Harris, Weststar, and McKenna (2015) talk about the extreme working conditions of the videogame production process by examining two very well-known whistleblowing blog posts from spouses of game developers at triple-A studios. From the panoptic office conditions where coders, artists, and developers routinely work in spaces that are meant to facilitate collaboration and work flow by eliminating privacy measures such as cubicle walls, office spaces, or even desk carols (complete with motion sensors in the ceiling to track who is working), to the "project-based" work that the videogame industry thrives off of (which breeds job uncertainty, and drives workers to 80+ hour work weeks (Legault \& Weststar, 2015; Peticca-Harris et al, 2015)), the videogame production process competes with the capitalist socius for creating bodies capable of - and trained to produce surplus capital at all times without any questions. Lionhead Studios' failure is just one example of hundreds where the capitalist socius's wanton disregard of the needs of the bodies in it led to a studio's closure. Burnout, depression, and health and family-related problems are all 
very real consequences of working in the industry (Johnson, 2013; Dyer-Witheford \& de Peuter, 2006; Bulut, 2014, 2015; Williams, 2013b, 2018).

The bodies at work creating and developing videogames are not the only bodies being remade by the videogame industry. In The Three Ecologies (1989), Guattari discusses the concept of Integrated World Capitalism (IWC), which Pindar and Sutton, in the translator's notes, define as:

Post-industrial capitalism - which Guattari calls Integrated World Capitalism (IWC) is delocalized and deterritorialized to such an extent that is impossible to locate the source of its power. IWC's most potent weapon for achieving social control without violence is the mass media.

In the case of videogame production and consumption, the television set, as Pindar and Sutton reference, is not the point of entrance; instead, we must look at the global networks behind the videogames we consume. In addition to the devastatingly stressful environments that videogame production takes place in, a good portion of that work is outsourced, contributing to further job instability and precarity. Hyman (2008) examines how the outsourcing practices of videogame art was an early harbinger of things to come. The company he profiles, THQ (today known as THQNordic), is a multi-billion dollar triple-A videogame producer that refers to outsourcing as 'distributed development.' Hyman references THQ having outsourced 20-25\% of their art asset development in 2008, whereas today they outsource somewhere around $80 \%$ of their art asset development. Their in-house production is now primarily game systems, proprietary art assets and marketing/branding. THQ's rampant outsourcing speaks to both the nature of the capitalist socius and of the videogame production process: what you keep in-house will end up costing you more than outsourcing. The majority of the art assets that THQ's internal developers outsource are to developing countries with burgeoning tech sectors like India, and increasingly Eastern Europe; this means that, for what would cost these internal developers millions of dollars to develop in-house, they can outsource for development at a fraction of the price.

In addition to the physical labour the bodies in question in videogame production engage in, the immaterial labour invested in games is another important aspect of IWC. Lazzarato (2010) defines immaterial labor as "the labor that produces the informational and cultural content of the commodity" (p. 132). Steinkuehler (2006) wrote about the international distribution and privilege of play in Lineage. She profiles the "Chinese farmer" ${ }^{1}$ " in Lineage II:

For-profit companies in China were hiring people to play Lineage II for virtual currency in exchange for real-world pay. The practice continues largely unchecked today, and the attending controversy has nothing but intensified. [...] As best as I can piece together, Chinese adena farmers normally work 12-hour shifts... with two people to each computer so that the in-game character they share is always online. Typically, they must collect 300,000 adena per shift in exchange for their daily wage of about US\$3. It may not sound like much, but compared to China's average yearly income of US\$316, it's rather lucrative work.

p.

\footnotetext{
1 "Chinese farmer" in this context references a person, often of Asian descent, who works in sweatshop conditions killing in-game enemies over and over again to harvest gold that is then sold to other players for real-world money.
} 
Dibbell (2016) built on this work, addressing the issues of whether paid gold farmers are players, and whether unpaid farmers are employees, echoing many of the same questions that have been asked in modding discourse (Kuchlich, 2005; Sotamaa, 2007; Gallagher et al, 2017; Lauteria, 2012). The immaterial labour taking place in both of these pieces further highlights the worldwide precarity of videogame culture. "Playbour" (Kuchlich, 2005) takes place as a means of making a living in third-world countries while this work is sold to Western players for inflated prices, and players who have the means can benefit and perpetuate the necessity of this labor by buying the gold and items these people farm, which gives those players an inherent advantage over other players.

Dibbell and Steinkuehler don't consider the mechanisms of discipline that gold-farming sweatshops incorporate that further subjectivate the bodies labouring in those spaces: the spaces in which these bodies farm virtual gold resembles the development areas of many triple-A game studios. There is no sense of privacy, and the "fun" that is associated with playing a videogame is absent in much the same way as other unrecognized areas of videogame production, for example QA testers suffering burnout and job instability (Bulut, 2014; Williams, 2013) and community managers being expected to respond to community issues 24/7 (Kerr \& Kelleher, 2015), to name a few. Both farmers and videogame production workers labour under conditions that do not value privacy, such as no partitions or cubicles, all the workers work in the open being monitored by management, they have quotas to meet, and they work grueling hours to meet those quotas (see Webster, 2018 for a discussion about Red Dead Redemption II's developers working 100 hour weeks to finish production). Both work spaces have a sense of panoptic control - the bodies labouring in these environments are being monitored, and should their work not be satisfactory, they can be replaced as quickly as they were hired.

\section{Subjectivation Station(s)}

Lazzarato (2010) says that capitalism:

...reveals a twofold cynicism: the "humanist" cynicism of assigning us individuality and preestablished roles (worker, consumer, unemployed, man/woman, artist, etc.) in which individuals are necessarily alienated; and the "dehumanizing" cynicism of including us in an assemblage that no longer distinguishes between human and non-human, subject and object, or words and things.

While capitalism is complicit in perpetuating hard binaries by creating and maintaining the material properties of bodily normativity by linking things such as gender to colors, masculinity or femininity to clothes and hygiene products, and masculinity/femininity to sports, it also allows rampant cultural subjectivation in other strata. For example, in the videogame production process, hypermasculinity, anti-feminism, and colonialism (white male saving a kingdom/town/woman from a non-human [read: non-white] threat) are common storylines in videogames. But the question remains: how, and why, are these tropes perpetuated, even in games that are supposed to be progressive and inclusive?

I want to start by addressing the binary of production/anti-production that Guattari (1996) references. Anti-production accounts for the things that are not getting made. Guattari refers to cinema as a medium of "transference, Oedipus, and castration" (p. 235), meaning that cinema produces cultural markers by which bodies in modern society become subjectivated to value 
certain standards of beauty, products, religious forms, and other marks of enculturation so as to make these things profitable and able to be monetized. In other words, Guattari alludes to cinema as being a trend-setting affair. It creates the 'cool' things that drive supply and demand. The case can be made, too, that videogames operate in much the same way as cinema insofar as they both subjectivate consumers to value certain products, bodies, and forms over others, and create value systems that other media incorporates or it runs the risk of failing. The value systems that tripleA game production values and perpetuates are tropes of anti-femininity, hypermasculinity, colonialism, etc.

In the instance of videogame production, a prime site of anti-production is personal-games games that are not 'marketable' in the current consumption model of capitalism, or are not meant to function within the subjectivation processes of the capitalist socius, likely meaning that the game would fail if released for a mass audience and for monetization. Often, personal-games tackle the issues that their creators face, and as such, find no market appeal or replayability outside of therapeutic use (Anthropy, 2012). In other words, the anti-productive elements of personal-game production is the game itself; the material and discursive productive process that goes into a videogame with the knowledge that it isn't meant to adhere to capitalistic logics, and that it is actively attempting to subvert tropes of hyper-masculinity and anti-feminism (in addition to anti-mental-health, anti-LBTQA, etc.).

Videogame production processes subsist on, historically, keeping this type of game out of mainstream production culture and instead of selling personal, affective experiences, selling iteratively different content to a quantifiable body (e.g. war games such as Call of Duty, Battlefield, Halo, etc. being marketed mostly to male, 18-35, heterosexual, white bodies). Current videogame production processes, though, are beginning to understand and recognize that affective and emotionally investing games can be monetized (Rusch, 2017; Isbister, 2017). So, whereas intimate, timely experiences that were rendered in videogame form used to be prevalent only in DIY and non-professional spaces (Fisher \& Harvey, 2013), the capitalist socius has begun to develop the tools to consume and repurpose these game types in service of capitalism. In professional videogame development spaces, the bodies creating these affective experiences and attachments have not changed either; in fact, the bodies in these spaces have stayed much the same (Weststar \& Legault, 2017; Williams, 2018; Fisher \& Harvey, 2013). This has fostered an increasingly toxic and predatory environment in which videogame production workers must labour under subjectivation regimes of not only being ok with creating and perpetuating antifeminine, hypermasculine, colonialist, and anti-homo/transsexual media, but now also affectively and emotionally predatory media as well, further instantiating the dehumanizing cynicism that Lazzarato talks about by expecting workers to cede any moral judgement or objections to projects.

Taylor, Jenson, and de Castell (2009) paint a picture of the toxic subjectivation that occurs at videogame conventions that, according to Johnson (2013), Williams (2013), and Bulut (2014), mirrors the working conditions and subjectivating conditions of modern videogame production culture. They outline the culture of "booth babes": conventionally attractive women hired by videogame companies to use their potential sex appeal to perform for, and attract, a core male audience to convention booths and subsequently sell products. At these videogame conventions, male bodies are there to game and engage in active consumerism, and female bodies are there in roles of support; either as eye-candy, affective and emotional support, or simply to further grease the wheels of capitalistic consumption. The cultural spaces that videogames inhabit have long 
been an "old boy's club" (Johnson, 2013a; Dyer-Witheford \& Sharman, 2005) in which women's bodies are marginalized - thought of as weak and needing to be rescued while men perpetuate hyper-masculine tropes of killing and colonizing (Paßen, Morgenroth, \& Stratemeyer, 2016). Women are attacked and their validity, personal and professional, is called into question (Fisher, 2015; Kerr \& Kelleher, 2015). They are ignored as audiences; thought to just be "...vacant pinups to be ogled or irrelevant sidekicks to be tolerated, and real women [are] annoying interlopers to be bullied" (Fisher, 2015). Even in instances of attempted diversification (Fisher \& Harvey, 2013), women's professional wants and needs are often ignored and downplayed.

Videogame production spaces are no better than most other cultural spaces concerning videogames where gender inclusivity and diversity are concerned. Johnson (2013a) talks about hyper-masculinity and the "boy's club" mentality of videogame production as something that:

some men...lamented..., [but] many of their explanations centered on the idea that the gender imbalance is simply due to the fact that more men than women apply for jobs in the industry. [...] other men offered a clearer window into the sexism of the digital play industry, explaining, for example, that 'girls' often do not have 'the right ideas' when it comes to games but that it 'looks good' for a developer to employ 'some girls...'

Not only are the culture and working spaces of videogame production hyper-masculine and homogenous, but that gender imbalance is what allows the industry to function in the highly racialized and gendered manner that it does. The temporal dimensions of the highly gendered and racialized nature of production spaces are not locked in splintered, non-connected events; the subjectivation of workers to include tropes that perpetuate dominance of one body type over another exists as a corporate culture and climate, not as one or two peoples' opinions that somehow manage to sneak into games. From conceptual stages through creation, conscious aesthetic choices by each person contributing to the videogame determines the continuity or usurping of hypermasculinity in both the production spaces, and in the products themselves (Johnson, 2013a).

Change in these realms does not happen with any sort of speed. Videogame production spaces are risk-averse and are often so locked to capitalistic production cycles that even if a studio wanted to rehabilitate its culture and spread that to production culture at large, breaking away from hypermasculinity and anti-femininity, which have proven to be selling points, often cannot happen due to the nature of stagnation that the capitalist socius favors. Simply put, slow, incremental changes to videogame IPs and genres is prized over innovation and newness (Johnson, 2013b). This perspective speaks to the Guattarian (1992) notion of heterogenesis as being

an active, immanent singularization of subjectivity, as opposed to a transcendent, universalizing and reductionist homogenization ... an expression of desire, of a becoming that is always in the process of adapting, transforming and modifying itself in relation to its environment. 
Heterogeny and iterative design are locked together in videogame production because they are part and parcel of what Guattari referred to with cinema (Guattari, 1996): videogame production is an enculturation endeavor and is responsible for subjectivating large sectors of the population. Capitalism has allowed videogame production to target certain audiences, readily subjectivize them to accept certain bodily, racial, and sexual portrayals as valid. Any attempt to break with those readily recognizable tropes would mean that the entire industry would have to radically reformat not only itself and who it is marketing to, or risk the entire medium crumbling in on itself from alienating faithful consumers. Again, this is played out in the culture of videogame production spaces; the bodies at work creating the subjectivizing material have themselves been subjectivized into accepting the validity of only certain bodies, and whether consciously or not, that subjectivization has embedded itself in workplace cultures that actively favor (mostly white) straight men for meritocratic purposes (D’Anastasio, 2018).

Large developers encourage heteogeniety throughout their studios. If the production processes and work flows are similar, it is easier to identify where and when a system is breaking down so that it can be rectified (Neilson \& Rossiter, 2005; Brooks, 1974; Crowley, Tope, Chamberlain, \& Hodon, 2010). If the work spaces are similar, it follows that, as more heterogenic elements are incorporated into the life of a studio, even games from different genres will start to emulate one another's systems and become mixed-genre media. And just as the games become more similar, the bodies that make those games are expected to become more similar. This is where the tropes of hypermasculinity and anti-feminism and anti-individualism start to become apparent. DyerWitheford and de Peuter (2006) state that "for many, the initially enjoyable aspects of work in digital play mutate into a linchpin of exploitative and exclusionary practices, including exclusion based upon gender."

Gender moderation is another aspect of production culture that contributes to the precarity of videogame production and perpetuation of negative tropes. Prescott and Bogg (2011) find that gender segregation is still happening in triple-A production spaces, and that women who do enter the industry must renegotiate their gender identity in order to fit in better with male coworkers (Johnson, 2013a, 2018). Johnson (2018) outlines how, if they do not do the work of renegotiating, they run the risk of being accused of being "fake gamers" (Taylor, Jenson, \& de Castell, 2009; D'Anastasio, 2018) and have their passion called into question. This further demonstrates an unwillingness on the part of male production workers to accept alternate forms of passion to their own, alternate forms of bodies, and what those bodies are capable of.

\section{A Platform for Platforms}

Platformization, as defined by Reuver et al (2018) is "the penetration of economic, governmental, and infrastructural extensions of digital platforms into the web and app ecosystems, fundamentally affecting the operations of the cultural industries" (2). Considering cultural penetration of economic and infrastructural forces, especially, becomes important to understanding how the capitalist socius has access to, at multiple levels, the bodies most at risk of subjectivation. Everything from how we access the internet to how ads are targeted to us on social media to autocomplete in emails comes from how embedded certain platforms are in our everyday lives. Fuchs (2011) says that 
Google has become ubiquitous in everyday life - it is shaping how we search, organize and perceive information in contexts like the workplace, private life, culture, politics, the household, shopping and consumption, entertainment, sports, etc. The phrase "to google" has even found its way into the vocabulary of some languages.

Alongside this ubiquity, Google is regarded in auspicious, almost pastoral terms by some sectors of popular media and business studies (see Vise, 2005; Tapscott \& Williams, 2006; Auletta, 2010 among many others). It is characterized as benevolent and non-threatening because, as Fuchs rightly assesses, the ways in which this platform has inundated our lives creates not only a sense of ubiquity, but also a sense of dependence that often goes uncriticized because it feels like it can't be criticized, lest we anger Google and lose the access to information that we currently have. But, as Zimmer (2010) points out, Google has monopolized information access, created a distorted sense of knowledge-production by algorithmically weighing the validity (therefore, the "truth") of certain sites, and created a tool that, by necessity of the way it is formed, requires a certain mastery (not unlike the mastery required to operate early text adventures) to yield results that the user may want, and not what the algorithms tell a user they want. This algorithmic subjectivation becomes an issue not only for common people browsing the internet, but also for multiple facets of media production and consumption, governmental control, and cultural generation. The question, then, is what happens when a user is not aware that they need a certain mastery to acquire impartial, or un-parsed, information? What happens to a cultural movement that is actively being surveilled, aggregated, and shaped by outside parties' access to search results, news items, social media presences, and even academic research?

Google's dominance as not only a search platform and web browsing platform, but an integrated home Internet of Things (IoT) platform, is found in its overpenetration and ubiquity to users in addition to its ability to aggregate data, now both physical data and digital data, from users that is then sold (Fuchs, 2011). Pulling from Marx (1894), we can understand Google users not simply as users, but as producers/consumers (what Toffler, 1980, called prosumers) whose unremunerated labour creates value surplus that Google is then able to monetize and manipulate. Google users who perform the labour of creating user-generated content, aggregating social media presences, and creating a digital footprint are providing productive labour that produces surplus that is then reabsorbed into the capitalist socius. All of this data that is being parsed through, aggregated, and monetized by Google also creates an economy of exploitation (Fuchs, 2011) that need to be considered. Economic consolidation, surveillance, and ideological/political power threat (Fuchs, 2011) are three considerations where, ultimately, monetized data being sold to the highest bidder threaten a truly equitable model of access that Google has stated that it stands for. It also threatens to create complete heterogeny of culture by way of capitalism dictating who sees and accesses what information.

This possible economy of exploitation only further entrenches the dangers of heterogenythrough-capitalism (-by-way-of-platformization). Similar platforms to Google, such as Apple, Facebook, and Amazon (collectively referred to as GAFA), follow the same model of passive data farming, making prosumers out of users, and exploiting the labour performed for no remuneration and selling information to the highest bidder (Barwise \& Watkins, 2018). These platforms are able to manipulate data to create cultural trends of their own through targeted, bombardment-style advertising and by giving users feedback opportunities about what ads they did and did not remember seeing. By the virtue of farming the data that the platforms subsist off, such as recording a video on your iPhone of a protest and uploading it to Facebook, or googling 
a product that then takes you to an Amazon link, these platforms collect surveillance data that is used to shape access to, and information about, organic, existing cultural trends. Additionally, these platforms are able to further leverage their ability not only as multinational, overpenetrative cultural entities, but as cultural trends themselves to further embed in users' lives and to create markers of cultural cache by which a person's cultural relevance can be quickly assessed. The insidious nature of platformization, especially of the entities that Barwise and Watkins (2018) examine, create a far-reaching cultural norm of heterogeny that is not seen as heterogeny, but is seen as stability. These entities' ways of subjectivation sees users committing to and perpetuating the moral, ethical, and consumeristic stances that the platform's creators deemed correct or relevant, create cultures of subjectivation that allow for the capitalist socius to monetize the mores of its subjectivated users, and also push users to further depths or prosumerism to keep producing surplus values that can be fed back into the platform ad infinitum.

\section{“Platformers:” But Not Games, Just Like... A Pun on Games}

In videogame production, platformization does not have as outwardly a penetrating and ubiquitous presence as GAFA platforms, but the platformization that does occur in videogame production creates verdant ground for the capitalist socius to create working environments that self-police for "culture fit" and difference (D'Anastasio, 2018), and actively seek to rid working environments of bodies that are not similarly subjectivated (Pettica-Harris, Weststar, McKenna, 2015). This creates work environments where masculinity and shows of masculinity are valued, especially the valorization of overwork (Webb, 2018; Williams, 2013), and different bodies and ideas are not allowed. By creating a working environment that valorizes overproduction while also valuing heterogeny in the bodies overproducing, the capitalist socius is provided with a selfsustaining environment that produces, self-regulates, and readily subjectivates potential future workers just by producing the media in question. The question I am interested in is how videogame production culture has become a platformization tool that, just as the capitalist socius has outfitted GAFA platforms to perpetuate their own forms of subjectivation via cultural uptake and shaping, which is then monetized, videogame production has been similarly kitted. Unlike GAFA platforms, though, there is no 'one name' (or four names) that videogame production can be likened to as a platform, so I will be using the term 'videogame production' broadly to reference the production cycle, working environments, and games being produced as the 'platform' in question.

While it is beyond the scope of this paper to provide a comprehensive historical account for how things such as passion for playing (Kerr \& Kelleher, 2015; Bulut, 2014), valorization of overwork (Williams, 2013; Johnson, 2013a; D'Anastasio, 2018), hypermasculinity (Johnson, 2013b, 2018; D'Anastasio, 2018) and "hegemonic play" (cf. Fron, Fullerton, Morie, and Pearce, 2007) have intermingled to create the assemblage of current triple-A game production worldwide, Fisher and Harvey (2013) provide a convenient case study that can be contextualized using work from other Canadian games scholars. This case study can be used to understand how platformization and the capitalist socius allow for negative tropes to embed and be used as training techniques, even when seeking to train marginal bodies for entry into videogame production. One concept becomes useful when thinking about how subjectivation occurs, especially in the case study that Fisher and Harvey present. Surplus value(s) of code (Deleuze \& Guattari, 1983) are code fragments from one machine that find their way into another machine 
(for Deleuze and Guattari, 'machine' could be bodies, organic material, inorganic material, etc.). Therefore, both machines become intertwined and the machine that captured the surplus value of code owes its unique existence to the first machine. In the case of human bodies, it follows that the initial 'machine', intent on subjectivating, is videogame production. The platform and the capitalist socius need workers that hold certain values and cultural markers to allow it to continue monetizing, which is where subjectivation comes into play. Workers and players alike capture pieces of code from videogame production in different ways that have different effects. One possible effect is the embedding and perpetuation of negative workplace tropes like valorizing overwork and antifeminism. Another effect, specific to consumers, is the capture of cultural signs that create markers upon which the consumer builds world views. This, then, shapes purchasing patterns, platform use, job choice, cultural mores, etc.

In the case of Fisher and Harvey (2013), I am less concerned about successful transference of surplus values of code, but rather, how those codes were rejected and rewritten, allowing for a schism to form in the smooth reproductive act of capitalism. To get to that schism, though, we must understand the cultural assemblage that Fisher and Harvey investigated. They say that "...technological and computing expertise in general continues to be largely associated with the constitution of hegemonic masculinities... it is unsurprising that there is a shortage of women working in the digital games industry." This means that, while diversity initiatives are at work in videogame production and there are efforts being made to make videogame production more equitable, hegemonic masculinities associated with videogamic spaces is not new, isolated to certain publishers or workplaces, or being blown out of proportion. Work from Connell (2009), Taylor, Jenson, and de Castell (2009), Corneliussen (2012), Hacker (1981), Lauteria (2012), Fisher (2015), Deuze, Martin, and Allen (2007), Dovey and Kennedy (2007), Eubanks (2018), Wajcman (1991), Hicks (2018) among many, many others traces out a lineage of heterosexual, white, masculine control not only over technology (Hacker, 1979, 1981), but of anything associated with technology. Understanding that control over technology and technology-adjacent things becomes important when considering how the capitalist socius allows for hypermasculinity to embed and perpetuate in videogame production culture, and how the stereotypical workplace culture and critiques of videogame production I've leveraged throughout this paper becomes platformized as well.

Dyer-Witheford and Sharman (2006) say about Canadian videogame production that "[most] Vancouver games studios contain some link back to EAC (Electronic Arts Canada). When EA bought Distinctive, a couple of the latter's founders, preferring to remain independent started Radical Entertainment. [...] Game making in Vancouver is a close-knot world, with EA at the centre of the web." They continue to say that, in Montreal, developer Ubisoft plays a similar role to EA: a genesis point where production workers work, learn, and then leave to go to other companies or start their own ventures. In a similar fashion to how GAFA platforms penetrate and subjectivate users' lives, work culture platforms can do the same thing. Fisher and Harvey (2013) examine how an incubator event in Toronto - Difference Engine Initiative (DEI) - was aiming to provide selected women participants with a support structure to develop and polish the competencies that are valued in digital game production in an attempt to rectify the gender imbalance perceived in Toronto. DEI's stated goal was to, partially, generate a dialogue about why women were not being included in videogame production, and, partially, to try and give women the tools needed to be successful. But, as Fisher and Harvey point out: "[even] the bestintentioned programs, practices, and people operate within the racist, heterosexist, patriarchal, 
and capitalist hegemonic orders they seek to topple." The first iteration of DEI proved to be no exception to well-meaning perpetuation of the things it sought to topple in that it reinforced negative stereotypes of what their target audience was and what they knew/could do (p. 30), and then the format of the incubator itself was

...a carbon copy of the Artsy Games Incubator (AGI), [a Hand Eye Society] program encouraging artists to extend their practice to games development. Significantly, the AGI did not have a social justice agenda, nor was it a female-only space. Yet organizers did not modify the AGI program for use in DEI1 -- everything from curriculum to delivery, remained untouched and was imported wholesale. This one size fits all approach to teaching game design - no matter who the participants are - ironically demonstrates an insensitivity to individual differences, as well as HES organizers' commitment to not disrupt established practices. When participants suggested alternative ways of doing things, these ideas were rejected because they challenged "how things are done.

As Fisher and Harvey mention earlier in the article, the intention of DEI1 was to be an intervention into what the overly-male-saturated Toronto videogame production scene saw as an issue of gender imbalance. The building and execution of DEI1 is an example of pastoral masculinity, or the tendency for masculinity to present in such a way that the male body/ies in question try and guide non-male bodies to a desired outcome that the male bodies deem most appropriate (Johnson, 2013a). Those in charge of the first DEI insisted on platformizing games education by reusing a template for game creation literacy training that, ostensibly, worked for AGI and refused to take into account the radically different, radically divergent wants and needs of its participants. DEIl sought to subjectivate these potential capital producers into the ways in which videogame production was "supposed" to be instead of considering that these women preferred and needed other forms of support aside from being jumped into a videogame production gang.

Though DEI1 was problematic in parts of its process, Fisher and Harvey (2013) point out that the entity itself (the incubator) brought a good amount of attention to women's game design and activist work within videogame production. DEI1 also shed light on ways that marginal bodies in videogame production in Toronto specifically can resist committing to gender moderation like I discussed earlier in order to fit in in videogame production workplaces, and instead, create new methods of support, metrics of success, and ways of subjectivating that do not prop up the capitalist socius.

\section{Starting a Revolution}

The bulk of this paper has attempted to pin down the ways in which videogame production, the capitalist socius, and platformization all intermingle in an assemblage that encourages heterogenous content, self-polices and self-selects (specifically through gender moderation) for bodies that are hypersubjectivated to produce and perpetuate tropes of overwork/antifeminism/hypmasculinity, and attempts to consume and monetize cultural markers, stripping them down from their intended community-focused empowerment (Condis, 2014; 
Ruberg \& Shaw, 2017) and monetizing them instead. Like every machine, the capitalist socius has weaknesses that exhibit possible ways of breaking out of the continual cycle of subjectivation and absorption, and instead create instances of resistance that, regardless of how minor, still impede the capitalist socius.

For Deleuze and Guattari (1983), one such site of resistance was the schizophrenic body. The process that the schizophrenic mind undergoes in processing information was of great importance to crafting a possible methodology of escape from the capital socius' crushing subjectivation. They do not fetishize schizophrenia as a disease, nor do they fetishize the bodies suffering from it. Instead, they aim to create a schizoanalytic framework not through which to understand and classify the mind and assign value markers to bodies like psychoanalysis did. Instead, Delueze and Guattari sought to understand how the schizophrenic process "... is the potential for revolution. [...] The choice is between one of two poles, the paranoiac counterescape that motivates all the conformist, reactionary, and fascisizing investments, and the schizophrenic escape convertible into a revolutionary investment." On the one hand, Deleuze and Guattari see the schizophrenic process as one that, instead of capturing value surpluses of code and embedding that new coding into the machine, creates a necessary moment of interruption. Instead of smooth reproduction of a cultural marker from subjectivating platform to body-beingsubjectivated, the schizophrenic process reveals a schism that allows for "...the structural unity of the machine [to be] undone..." (p. 304). Deleuze and Guattari assign fascist political value to the capitalist socius because of its insistence on subjectivating bodies for the pure purpose of producing excess capital that is then hoarded instead of shared. This production extends to money, knowledge, material resources, and ideological resources. The capitalist socius' counterpoint, schizorevolution, is non-fascistic, not concerned with hoarding resources, nor with perpetuating binarisms and identity markers. Instead, schizorevolution seeks to allow bodies trapped within the capitalist socius to use the productive form of their desire to produce things that are 'worthless' (read: not readily monetizable, or not easily monetizable) to the capitalist socius, thereby freeing the body in question from the continual subjectivation and resubjectivation as the capitalist socius changes and evolves. In this section, I want to examine two places where capturing value surpluses of code in videogame production breaks down and can allow for schizorevolution.

The first place is game design groups that embody the same ethics of care that DEI2 did: listening to participants, adjusting based on their wants and needs, and providing a place where the pressure to become "industry ready" did not manifest in perpetuations of the negative workplace culture of triple-A game creation. The second place is in unionization efforts of videogame production workers. Williams (2018) details how, after decades of exploitative, abusive work practices characterizing the production process, a number of videogame production workers have started movements towards unionization in an effort to establish work-life balance and to reconfigure how they approach videogame production.

\section{Game Creation Groups}

DEI1 caused a shift in Toronto's game development scene; it showcased how, sometimes, the best intentioned things go wrong, and how important it is to do the diligence of getting to know your core audience when creating something like an incubator, lest the incubator repeats and entrenches the same themes that it was originally supposed to usurp. It also created an environment where "...participants and allies were more eager than ever to work towards 
fostering a more inclusive indie game development community in Toronto" (Fisher and Harvey, 2013). One major creative break from the typical industry-focused environment of production in Toronto became Dames Making Games (DMG). It became a community that focuses on supporting women in game development, community support, networking opportunities, and outreach (see: Westecott, 2013, and @DMGToronto on twitter). Their website states that:

DMG is specifically for genderqueer, nonbinary, femme people, Two Spirit people, and trans and cis women. / DMG is an explicitly feminist space but open to any and all genders. / We prioritize people who are traditionally marginalized in tech and game spaces, especially those whom DMG specifically serves, as well as people who are racialized, neurodiverse, and/or have disabilities.

Faber, $2018-\underline{\text { link }}$

Their commitment to marginal bodies within videogame production creates a schism in conventional capitalistic videogame production logic. Instead of pushing a heteorogenous and male-dominated-industry-focused curriculum and socialization/networking scheme that seeks to subjectivate non-male potential producers to commit to and get used to "how things are/are done" in videogame production, DMG continues to support the mission and ethos of DEI2. By creating spaces for women in videogame production that are not directly concerned with churning out industry-ready, industry-subjectivated bodies, DMG has created a schizorevolutionary space where there used to be only capitalistic subjectivation and platformization at work.

Evans (2018) created a women-only beginner's game design workshop at North Carolina State University with much the same intention as DMG; providing women with a space where, regardless of coding skill or videogame knowledge/experience, they could hang out, talk shop, play and make videogames together without the pressure of "being industry ready" or emphasis being put on how they could monetize their games. The group met in Evans' PhD program's technology space, Circuit Studio: a highly technologized spaces meant for students in the PhD program to experiment with technology like eye-tracking software, game consoles, Arduinos, touchboards, and 3D printers. It is a masculine-coded space by nature of the bevvy of highly technical instruments in its confines (most without original boxes/packaging or instructions), but the space itself was mainly only inhabited by male bodies studying, hanging out, playing games on the projectors, etc. What Evans sought to do by holding her game design group in this space was recontextualize how she and other women in the program interacted with the space, and create a space within this heteorogenous, masculine zone that refocused primacy away from technological bodies back onto human bodies. Evans' approach to the concept of "game design" was also fundamentally different than how other game design groups would approach teaching beginners. Evans encouraged paper prototyping, crafting, and creating non-digital representations of characters, themes, and game designs as a way of, again, taking primacy away from the digital and resituating it onto bodies. The games that were created in Evans' game design group ranged in technical complexity from simple Twine games with few advanced techniques to fully-rendered games in RPGMaker. The focus, though, was not on the games themselves; Evans was explicit that the focus on the group was not to prepare these women to go into the videogame industry, or even to get them interested in learning coding and game design themselves. The group was meant to foster an ethic of care so many technologized spaces lack, and so many game development spaces especially lack. Evans provided payment for each of her 
participants for each week they attended, and she provided healthy snacks for participants as well. Even something as simple as the mindfulness that went into the snacks that Evans provided to participants denotes a fundamental and important shift away from the penitent for videogame production spaces to provide energy drinks, junk food and other "quick" snacks, and instead offer healthier choices for participants. This primacy on health/healthier food choices over quick and easy food choices reflects Evans' own experience examining game jams - especially game jams that were marketed as 'feminist'. She found that the food choices between regular game jams and 'feminist' game jams were almost always the same unhealthy, sugar-laden food meant to prop up a body for the 24 hours that the game jam lasted (Evans, personal communication, March, 2018).

In addition to wanting to sustain the bodies in her game design group instead of just prop them up to produce, the ethic of care that this group embodied was another schizorevolutionary facet that most game development groups and game jams that Evans had examined did not support. Failure was an inherent part of Evans' game development group; from the paper prototyping/crafting stage all the way through debugging and troubleshooting end products. The ways in which failure was handled, and how failure was not labeled as "failure" but as an iterative learning experience presented a diametrically opposed view of what iterative game design encompasses traditionally (see Sharp \& Macklin, 2016). Evans' definition of failure in her design group fostered an environment akin to how Halberstam (2011) and Munoz (2009) characterizes failure as a line of flight from capitalistic logics; something that creates a new beginning, a new way of interaction. Some of the games that Evans' participants produced did not function like they were coded to. Instead, they failed to execute certain commands, which then created new meaning both to the user and to the creator. In one instance, one mistake led to a game being about mistakes; the entire game was coded around mistakes in Twine that, instead of creating a linear story about a certain emotion, instead attempted to embody the jarring emotionality of that feeling in the very bones of the game and allow users to experience this feeling the same way the creator felt it. Evans (2018) referred to this in her dissertation as an iterative experience; a 'mistaken experience'. When thinking about iterative game design, the end product is very clear, and the design process is very clear as well; there is no room for not only allowing bugs, but actively incorporating them into a game that will be sold (Sharp \& Macklin, 2016). Even affectively-driven game design, like what Isbister (2017) and Rusch (2018) talk about, do not have the built-in allowance of functioning around mistakes; these texts are obviously written for industry-focused game designers, and the ethic of care that Evans fostered creates an environment that is inherently unmonetizable.

\section{Unionization Efforts}

We have read time and again popular press articles that address open, unabashed exploitation of workers in videogame production spaces (Williams, 2015, 2018; Schrier, 2016; Kunzelman, 2017) and academic pieces that chronicle the ramifications that this exploitation has on entrenching the subjectivation that this paper has laboured to explain (Bulut, 2014, 2015; Johnson, 2013, 2018; Deuze, Martin, \& Allen, 2007; Dyer-Witheford \& de Peuter, 2006; Weststar \& Legault, 2017; Pettica-Harris, Weststar, McKenna, 2015). But there has not been much, if any, action towards rectifying this situation for North American videogame developers. Until 2018's Game Developer's Conference (GDC) where Jen MacLean, executive director of 
International Game Developers Association (IGDA), or the representative body for game developers, was set to give a roundtable titled "Union Now? Pros, Cons, and Consequences of Unionization for Game Devs Rountable." What started as a small Facebook group that was openly organizing against the idea that, in any way, consequences should befall workers who sought unionization, bloomed into a large community on Twitter (@GameWorkersUnite and (GWU_UK). The same organization that is meant to protect, lobby for, and support game developers, fired a shot across the bow about unionization, implying that there would be ramifications from game development companies should workers seek to unionize in any capacity. Expectedly, the roundtable was tense, it was packed to standing-room only, and MacLean's stance towards unions and unionization increasingly became a strawperson argument that placed blame on workers in the industry. MacLean said in a 2018 interview with Matt Kim at USGamer that "a lot of studios out there that crunch are very well known for crunching. When you go to work there, it's not a surprise when you're asked to work 60-70 hour weeks." As Williams so succinctly says: "This not only states that the employee should've known better than going to that crunchy studio if they end up unhappy, but it is expressly a defense of crunch. It's just how some studios operate." The thrust of this paper has been about 'how do we understand the capitalist socius' complicity in subjectivating workers to accept abusive and outrightly exploitive work practices and workplace cultures.' And the answer is stunningly simple: "It's just how some studios operate."

This sort of agency displacement has become a tactic in how studios characterize the exploitative working conditions and working culture: it's never one person or a group of people who are asking workers to perform the labour. Blame is always placed "on the project" (Bulut, 2014) or "on the studio" (Williams, 2018; Johnson, 2013b) and workers' passion is called into question if they complain about work conditions (Bulut, 2015). Since passion plays such an integral roll in recruitment and retention of game industry workers (Kerr \& Kelleher, 2015; Johnson, 2013, 2018; Bulut, 2014, 2015; Deuze, Martin, \& Allen, 2007; Weststar \& Legault, 2017) there is no wonder that this nebulous blame placement has entrenched itself in the industry and become less of a tangible, actionable issue, and instead "just how some studios operate;" not to be questioned, not to be challenged, just taken as not $a$ norm of an industry, but the norm of an industry.

Regardless of how unionization efforts have come about for North American videogame production workers, they are here, and an adequate understanding of the ramifications that this could bring is necessary. While there are issues of representation on many different levels that need to be accounted for and examined within any unionization movement such as how, historically with union discourse and bargaining, already-vulnerable populations often end up worse off or more exploited than pre-unionization (Garcia, 2012; Kemp \& Coverman, 1989), the very thought of North American videogame production workers unionizing creates a threat to the capitalist socius. The industry has, to this point, subsisted on exploitative labour practices, the valorization of overwork, and hypermasculinity as foundations that allow the capitalist socius to subjectivate workers to continue accepting and perpetuating these working conditions and cultures. To threaten this status quo with a potential reconfiguration of how labour is conceived of and carried out is schizorevolutionary in and of itself. French games labourers formed their own, independent union called Le Syndicat des Travailleurs et Travailleuses du Jeu Vidéo (LSTTJV) in 2017 to fight back against rampant underpayment and overwork. Their aim is to 
protect the interests of everyone associated with games labour - researchers, teachers, developers, artists, streamers, etc. - and they have gained international media attention in their coverage and support of Eugen Systems workers' strike in late 2018. LSTTJV used twitter, their website, Facebook, and word of mouth to spread the news of exploitation that Eugen Systems has subjected workers to and acted as a community touch-point for sympathetic parties to support the striking workers monetarily. Though this may not seem like much in the way of a schizorevolutionary action plan, public attention, impartial reporting and archiving, and monetarily supporting striking workers demonstrate a willingness to take direct action in supporting workers fighting against unfair work practices.

Unionization efforts in videogame production are still very formative. But, as LSTTJV and Game Workers Unite have demonstrated, the potential for unionization in videogame production presents a direct threat to the capitalist socius' ability to continue subjectivating bodies into accepting the abusive and exploitative work cultures that have been in place for years. Each of these entities have overlapping ethical and cultural goals: pushing for legislative bodies to help protect contingent and marginal workers, especially, from exploitation; informing workers of their rights; informing public institutions and associations of workers' rights, workers' needs and wants, and ways to support workers; and promoting alternative ways of organizing, supporting, and empowering members of the game production community (STJV.fr, 2019; gameworkersunite.org, 2019). These grassroots attempts to disrupt what is currently a highly problematic process present not only a direct, actionable dismantling of the capitalist socius' subjectivation efforts, but it also puts the platformization efforts that the capitalist socius engages in in a position of precarity. By insisting on spreading awareness to current videogame production workers of what their rights are, covering and archiving labour disputes in videogame production, and creating community-building focused online presences, these unionization entities are functioning in much the same way as Evans' (2018) game development group, and Dames Making Games. Both of these sites of resistance present schizorevolutionary possibilities to fundamentally restructure the ways in which workers engage with and perform labour in this industry.

\section{It's Not 'Goodbye,' Just 'See You Later'}

Throughout this paper, I have tried to locate where systems of capitalism can overlay onto the process of videogame production, creating a system of subjectivation that sees negative tropes such as hypermasculinity, valorization of overwork, anti-feminism, homo/transphobia, and colonialism among many others embedded in videogame production process and workplace culture. By incorporating Deleuzoguattarian concepts such as the capitalist socius, heterogeny, integrated world capitalism, and schizorevolution, I have provided the start of a framework by which videogame production as a practice can be interrogated more critically, in addition to current feminist and queer work regarding subject matter of games and perpetuation of aforementioned stereotypes. By including an understanding of and emphasis on how platformization works with the capitalist socius to create points of subjectivation in videogame production that are not time-dependent or place-dependent, but ubiquitous, I have opened up 
further dialogue options about how the workplace culture of videogame production embodies the aforementioned negative tropes, and why. All of this taken together, admittedly, paints a rather grim picture of the entirety of videogame production. That is not my express intention. The bulk of this paper makes very clear that there are a spate of problems in videogame production that are allowing for the process and the workplaces themselves to continue being exclusive, hypermasculine spaces. I chose to end this paper by discussing two issues of great importance to me as a scholar: positive examples of action that doesn't just pay lip service to "creating diversity" and "breaking down barriers", but actually does them. Though these examples are, for the most part, fledglings in the grand history of videogames, they represent important interventions that, for the purpose of this paper, reveal that the capitalist socius is not indestructible - just that it takes some creativity to find ways to gum up the works and create things that are not easy for the capitalist socius to consume and spit out a monetized version of.

This paper is not an exhaustive list of any sort. There are many other Deleuzoguattarian concepts that could help expand this framework. There is a much deeper, more nuanced understanding of platformization that exposes how political economies form around platforms, and in the spaces between platforms. There are many other feminist game design groups that are operating in the same ways that DMG and Evans' groups have and do. There are other potential schizorevolutionary acts in game development and production that this paper's concepts were not right to cover; chiefly among other acts is personal games. The genre of personal games introduce potential ways and means of game creation that render the games being made so deeply personal and so fundamentally unmonetizable that the capitalist socius would have a hard time absorbing them. Inherent to the design of some personal games is how they function in cultural settings as beacons to disenfranchised and marginal populations. Personal games about gender dysphoria and transitioning (Dys4ia, Anthropy, 2012), depression, (Elude, Rusch, 2017), detachment (Emily is Away, Seeley, 2015), air quality in China (Hazy Days, Ren, 2016), getting an abortion (Trapped, pig3on, 2016) and a litany of other games are shining examples of how creating a game can be both a cultural marker of great importance and inherently useless to the capitalist socius' quest for further monetizable products. Personal games are not perfect, however. As the capitalist socius has evolved, emotion has become more and more monetizable. Games such as That Dragon, Cancer (Green, 2016) tell the same types of narratives meant to evoke empathy, but they have a price tag attached, whereas the prior games I talked about do not. This brings up the question of subsistence in the capitalist socius. Until late capitalism full on breaks down, game developers also have to eat and pay rent. As noble as putting an affectivelydriven game up online for free is, the game itself does not generate the minimum needed by the developer to survive.

This presents an opportunity to return to Marxism and parse through where labour like this really falls. Is game development inherently part of the capitalist socius because it relies on things like electricity, computers, software, mice and keyboards or controllers, etc. to be able to access, build, and play them? And regardless of what game developers do, regardless of if they generate money off their product or not, free games aren't actually schizorevolutionary? Are game developers who are putting their work out for free creating conditions of exploitation and unfair 
pressure towards other developers who rely on games as their means of income? This paper does not have those answers, unfortunately.

One other "further research" item to be addressed is how gender is navigated in the current assemblage of videogame production, and the ways in which the binarisms inherent to capitalism can't be altered to allow for more inclusive game production until they are dismantled. I touched on gender moderation, but there is a treasure trove of feminist, materialist literature that could be tapped to provide a fuller understanding of the material-discursive elements of videogame production that compliment the topics I've covered in this paper. The future for this line of inquiry is bright and these questions are integral support structures for current and future feminist and queer inquiry into, and redesign of practices of, game design and game production.

\section{Bibliography}

Anthropy, A. (2012). Rise of the videogame zinesters: How freaks, normals, amateurs, artists, dreamers, dropouts, queers, housewives, and people like you are taking back an art form. Seven Stories Press.

Auletta, K. (2010). Googled: The end of the world as we know it. Virgin Books.

Barwise, T. P., \& Watkins. L. (2018). The evolution of digital dominance: How and why we got to GAFA. In M. Moore and D. Tambini (Eds.) Digital dominance: The power of Google, Amazon, Facebook, and Apple (pp. 21-49). Oxford University Press.

Behm-Morawitz, E., \& Mastro, D. (2009). The effects of the sexualization of female video game characters on gender stereotyping and female self-concept. Sex Roles, 61(11-12), 808-823.

Brooks, F. P. (1975). The mythical man month: Essays on software engineering. AddisonWesley.

Bulut, E. (2014). Playboring in the tester pit. Television \& New Media, 16(3), 240-258.

Bulut, E. (2015). Glamor above, precarity below: Immaterial labor in the video game industry. Critical Studies in Media Communication, 32(3), 193-207. 
Chess, S., Evans, N.J., \& Bains, J.J. (2016). What does a gamer look like? Video games, advertising, and diversity. Television \& New Media, 18(1), 37-57.

Chess, S. (2016). The queer case of video games: Orgasms, heteronormativity, and video game narrative. Critical Studies in Media Communication, 33(1), 84-94.

Condis, M. (2014). No homosexuals in star wars? BioWare, 'gamer' identity, and the politics of privilege in a convergence culture. Convergence: The International Journal of Research into New Media Technologies, 21(2), 198-212.

Connell, R. Gender: In world perspective. Polity, 2009.

Corneliussen, H. Gender-technology relations: Exploring stability and change. Palgrave Macmillan, 2012.

Crowley, M., Tope, D., Chamberlain, L.J., \& Hodson, R. (2010). Neo-Taylorism at work: Occupational change in the post-Fordist era. Social Problems, 57(3), 421-447.

D'Anastasio, C. (2018, August). Inside the culture of sexism at riot games. Kotaku. Retrieved from kotaku.com/inside-the-culture-of-sexism-at-riot-games-1828165483.

Deleuze, G., \& Guattari, F. (1983). Anti-Oedipus: Capitalism and schizophrenia. University of Minnesota Press.

de Reuver, M., Sørenson, C., \& Basole, R. C. (2018). The digital platform: A research agenda. Journal of Information Technology, 33(2), 124-135.

Deuze, M., Martin, C. B., \& Allen, C. (2007). The professional identity of gameworkers. Convergence: The International Journal of Research into New Media Technologies, 13(4), 335-353.

Dibbell, J. (2016). Invisible labor, invisible play: Online gold farming and the boundary between jobs and games. Vanderbilt Journal of Entertainment \& Technology Law, 18(3), 419-465.

Disalvo, B., Guzdial, M., Meadows, C., Perry, K., McKlin, T., \& Bruckman, A. (2013). Workifying games. Proceeding of the 44th ACM: Technical Symposium on Computer Science Education - SIGCSE'13.

Dovey, J., \& Kennedy, H. (2007). From margin to center: Biographies of technicity and the construction of hegemonic games culture. In J. P. Williams and J. H. Smith (Eds.) Players realm: Studies on the culture of videogames and gaming (pp. 131-153). Jefferson, NC: McFarland \& Company.

Dyer-Witheford, N., \& De Peuter, G. S. (2006). 'EA spouse' and the crisis of video game labour: Enjoyment, exclusion, exploitation, and exodus. Canadian Journal of Communication, 31(3).

Dyer-Witheford, N., \& Sharman, Z. (2006). The political economy of Canada's video and computer game industry. Canadian Journal of Communication, 30(2).

Evans, S. B. (2018). Disruption by design: Feminist interventions in digital game production on a university campus (Doctoral dissertation). North Carolina State University.

Faber, J. R. (2018). Introduction. Member Manual, Dames Making Games, Retreived from https://manual.dmg.to/

Fisher, H. D. (2015). Sexy, dangerous -- and ignored: An in depth review of the representation of women in select video game magazines. Games and Cultre, 10(6), 551-570.

Fisher, S., \& Harvey, A. (2013). Intervention for inclusivity: Gender politics and indie game development. Loading... The Journal of the Canadian Game Studies Association, 7(11).

Fron, J., Fullerton, T., Morie, J. F., \& Pearce, C. (2007). The hegemony of play. Proceedings from, DiGRA: Situated Play (pp. 308-319). Tokyo. 
Fuchs, C. (2011). A contribution to the critique of the political economy of Google. Fast Capitalism, 8(1).

Gallagher, R., Jong, C., \& Sinervo, K. A. (2017). Who wrote the elder scrolls?: Modders, developers, and the mythology of bethesda softworks." Loading...The Journal of the Canadian Game Studies Association, 10(16).

Game Workers Unite! (2018). Retrieved from www.gameworkersunite.org/about-us.

Garcia, R. J. (2012). Marginal workers: How legal fault lines divide workers and leave them without protection. New York University Press.

Guattari, F. (1996). Chaosophy: Texts and interviews 1972-1977 (L. Sylvère, Trans.). Semiotext(e).

Guattari F. (1989). The three ecologies. Bloomsbury.

Guattari, F.(1995). Chaosmosis: An ethico-aesthetic paradigm. Indiana University Press.

Guattari, F. (1981). Integrated world capitalism and molecular revolution. Presented at the Conference on Information and/as New Spaces of Liberty, Rio de Janeiro.

Hacker, S. L. (1979). Sex stratification, technology and organizational change: A longitudinal case study of AT\&T. Social Problems, 26(5), 539-557.

Hacker, S. L. (1981). The culture of engineering: Woman, workplace and machine. Women's Studies International Quarterly, 4(3), 341-353.

Halberstam, J. (2011). The queer art of failure. Duke University Press.

Hicks, M. (2018). Programmed inequality: How Britain discarded women technologists and lost its edge in computing. MIT Press.

Hyman, P. (2008). OUTSOURCING: Video game art is increasingly 'to go.' Game Developer, $15(8), 7-10$.

Isbister, K. (2017). How games move us: Emotion by design. The MIT Press.

Jenson, J., \& de Castell, S. (2018). 'The entrepreneurial gamer': Regendering the order of play. Games and Culture, 13(7), 728-746.

Johnson, R. (2013). Hiding in plain sight: Reproducing masculine culture at a video game studio. Communication, Culture \& Critique, 7(4), 578-594.

Johnson, R. (2018). Technomasculinity and its influence in video game production. In N. Theil Taylor \& G. Voorhees (Eds.), Masculinities in play (pp. 249-262). Palgrave Macmillan.

Johnson, R. (2013). Toward greater production diversity. Games and Culture, 8(3), 136-160.

Kemp, A. A., \& Coverman, S. (1989). Marginal jobs or marginal workers: Identifying sex differences in low-skill occupations. Sociological Focus, 22(1), 19-37.

Kennedy, H. (2002). Lara Croft: Feminist icon or cyberbimbo? On the limits of textual analysis. Game Studies, 2(2).

Kerr, A., \& Kelleher, J. D. (2015). The recruitment of passion and community in the service of capital: Community managers in the digital games industry. Critical Studies in Media Communication, 32(3), 177-192.

Kim, M. (2018). IGDA director says capital, not unions, will keep game development jobs secure. US Gamer. Retrieved from https://www.usgamer.net/articles/igda-director-unioncrunch-interview.

Kuchlich, J. (2005). Precarious playbour: Modders and the digital games industry. The Fibreculture Journal, 5.

Kunzelman, C. (2017, Aug. 23). Crunch culture is never just about individual choice. Waypoint, $V I C E$. Retrieved from waypoint.vice.com/en_us/article/kzznee/crunch-culture-is-neverjust-about-individual-choice. 
Lauteria, E. (2012). Ga(y)Mer theory: Queer modding as resistance. Reconstruction, 12(2), 7.

Lazzarato, M. (2014). Signs and machines: Capitalism and the production of subjectivity. Semiotext(e).

Legault, M. J., \& Weststar, J. (2015). The capacity for mobilization in project-based cultural work: A case of the video game industry. Canadian Journal of Communication, 40(2), 203-221.

Llerena, P., Burger-Helmchen, T., \& Cohendet, P. (2009). Division of labor and division of knowledge: A case study of innovation in the video game industry. In U. Cantner, J. L. Gaffard, \& L. Nesta (Eds.) Schumpeterian perspectives on innovation, competition and growth (pp. 315-333). Springer-Verlag Berlin Heidelberg.

Macklin, C., \& Sharp, J. (2016). Games, design and play a detailed approach to iterative game design. Addison-Wesley.

Marx, K. (1894). Capital, Volume III. London: Penguin.

Muñoz, J. E. (2009). Cruising utopia: The then and there of queer futurity. New York University Press.

Neilson, B., \& Rossiter, N. (2005). From precarity to precariousness and back again: Labour, life and unstable networks. The Fibreculture Journal, 5.

Nieborg, D. B., \& Poell, T. (2018). The platformization of cultural production: Theorizing the contingent cultural commodity. New Media \& Society, 20(11), 4275-4292.

Paaßen, B., Morgenroth, T., \& Stratemeyer, M. (2016). What is a true gamer? The male gamer stereotype and the marginalization of women in video game culture. Sex Roles, 76(7-8), 421-435.

Parker, F. Whitson, J. \& Bart, S. (2017). Megabooth: The cultural intermediation of indie games. New Media \& Society, 20(5), 1953-1972.

Peticca-Harris, A., Weststar, J., \& McKenna, S. (2015). The perils of project-based work: Attempting resistance to extreme work practices in video game development. Organization, 22(4), 570-587.

Prescott, J., \& Bogg, J. (2010). The computer games industry. In A. Cater-Steel \& E. Cater (Eds.) Women in engineering, science and technology: Education and career challenges (pp. 138-158). Engineering Science Reference.

Riegle-Crumb, C., \& King, B (2010). Questioning a white male advantage in STEM. Educational Researcher, 39(9), 656-664.

Ruberg, B., \& Shaw, A. (2017). Queer game studies. University of Minnesota Press.

Rusch, D. C. (2017). Making deep games: Designing games with meaning and purpose. CRC Press, Taylor \& Francis Group.

Salter, A., \& Blodgett, B. Hypermasculinity \& dickwolves: The contentious role of women in the new gaming public. Journal of Broadcasting \& Electronic Media, 56(3), 401-416.

Schreier, J. (2016, September 26). The horrible world of video game crunch. Kotaku. Retrieved from kotaku.com/crunch-time-why-game-developers-work-such-insane-hours1704744577.

Shaw, A., \& Chess, S. (2017). Reflections on the casual game market in a post gamergate world. In T. Leaver \& M. Willson (Eds.), Social, casual and mobile games: The Changing Gaming Landscape (pp. 277-289). Bloomsbury.

Shaw, A. (2014). Gaming at the edge: Sexuality and gender at the margins of gamer culture. University of Minnesota Press. 
Shaw, A. (2011). Do you identify as a gamer? Gender, race, sexuality, and gamer identity. New Media \& Society, 14(1), 28-44.

Sotamaa, O. (2007). On modder labour, commodification of play, and mod competitions. First Monday, 12(9).

Steinkuehler, C. The mangle of play. Games and Culture, 1(3), 199-213.

STJV. (2018). Version Française, Le Syndicat Des Travailleurs Et Travailleuses Du Jeu Vidéo. Retrieved from www.stjv.fr/en/.

Tapscott, D., \& Williams, A. D. (2006). Wikinomics: How mass collaboration changes everything. London: Penguin.

Taylor, N., Jenson, J. \& de Castell, S. (2009). Cheerleaders/booth babes/halo hoes: Pro-Gaming, gender and jobs for the boys. Digital Creativity, 20(4), 239-252.

Toffler, A. (1980). The third wave. Bantam Books.

Vise, D. A. (2005). Google story. Dunod.

Wajcman, J. (1991). Feminism confronts technology. Penn State University Press.

Webster, A. (2018, October 15). Rockstar clarifies red dead redemption 2's '100-hour work week,' following backlash. The Verge, Retrieved from www.theverge.com/2018/10/15/17979606/rockstar-red-dead-redemption-2-crunch-100hour-work-week.

Westecott, E. (2013). Independent game development as craft." Loading... The Journal of the Canadian Game Studies Association, 7(11).

Weststar, J., \& Legault, M. J. (2017). Why might a videogame developer join a union? Labor Studies Journal, 42(4), 295-321.

Williams, I. (2018, March 23). After destroying lives for decades, gaming is finally talking unionization. Waypoint. Retreived from waypoint.vice.com/en_us/article/7xdv5e/afterdestroying-lives-for-decades-gaming-is-finally-talking-unionization.

Williams, I. (2015, February 18). Crunched: Has the games industry stopped exploiting its workforce? The Guardian. Retrieved from www.theguardian.com/technology/2015/feb/18/crunched-games-industry-exploitingworkforce-ea-spouse-software.

Williams, I. (2013). 'You can sleep here all night': Video games and labor. Jacobin. Retrieved from www.jacobinmag.com/2013/11/video-game-industry/.

Zimmer, M. (2009). Web search studies: Multidisciplinary perspectives on web search engines. In J. Hunsinger, L. Klastrup, \& M. Allen (Eds.), International Handbook of Internet Research (pp. 507-521). Springer, Dordrecht.

\section{Ludology}

Anthropy, A. (2012). Dys4ia. PC.

Green, R. (2016). That Dragon, Cancer. Android, iOS, PC, Mac, Ouya.

pig3on. (2016). Trapped. PC.

Ren, M. (2016). Hazy Days. PC.

Rusch, D. (2017). Elude. PC. 